\title{
VALUE IN USE OF PASEK DUNITE IN THE BOF PROCESS*
}

\author{
Cristina Escudero Martinez ${ }^{1}$ \\ Javier Martinez Rubio ${ }^{2}$ \\ Esteban Ruisanchez Rodriguez ${ }^{3}$
}

\begin{abstract}
The purpose of the Basic Oxygen Steelmaking (BOS) is to refine the hot metal produced in the blast furnace into raw liquid steel, which may be subsequently refined in the secondary steelmaking shop. Appropriated fluxes for the BOF could require low melting point to reduce the energy consumption, to reduce the energy to fluidity the slag at lower temperature and to melt at lower temperature than steel. It is necessary a good Tumble test result and the fluxes do not generate fines which could obstruct the blowing plugs, so we would have a homogeneous flux. A homogeneous chemistry that allows to control the basicity ( $\mathrm{Si}$ and $\mathrm{MgO}$ levels) and a high absorption characteristics to combine the flux with $\mathrm{P}, \mathrm{S}$, Si, etc. are necessary. PASEK Dunite is an ultramaphic rock exploited in the north of Spain with a basic chemical classification being olivine and serpentine its principal minerals. It is formed by orthopyroxene, clinopyroxene and olivine in variable proportion. Dunite is a very homogeneous and hard stone. The main characteristics are: High hot and cold resistance to mechanical stress (shatter / crushing / abrasion), softening and melting points of a flux, not a refractory material, large porosity which is increased more than $20 \%$ when dunite is heated at BOF process temperature, and high absorption level, and stable components with low melting points. PASEK Dunite is a good flux in BOF process and its use is recommended if the BOF process produces pig iron with low Si content, generates high levels of slag and it is necessary maintaining the basicity index and the $\mathrm{MgO}$ amount and with high value of hot metal ratio (high amount of phosphorus to remove). Keywords: Fluxes; Dunite; BOF; Magnesium silicate.
\end{abstract}

1 Mining Engineer, Technician, Commercial Department, Pasek Minerales SAU, Salinas, Asturias, Spain.

2 Mining Engineer, General Manager, Management, Pasek Minerales SAU, Salinas, Asturias, Spain.

3 Mining Engineer, Business Development Manager, Commercial Department, Pasek Minerales, Salinas, Asturias, Spain. 


\section{INTRODUCTION}

\subsection{Objective of the Converter}

The purpose of the Basic Oxygen Steelmaking (BOS) is to refine the hot metal produced in the blast furnace into raw liquid steel, which may be subsequently refined in the secondary steelmaking shop. In the Figure 1, is shown a typical BOF process; the different raw materials and the composition of each product.

The extent of refining in oxygen steelmaking processes is substantial since the principal metallic feed is blast furnace hot metal containing high percentages of carbon, silicon, phosphorus and manganese.

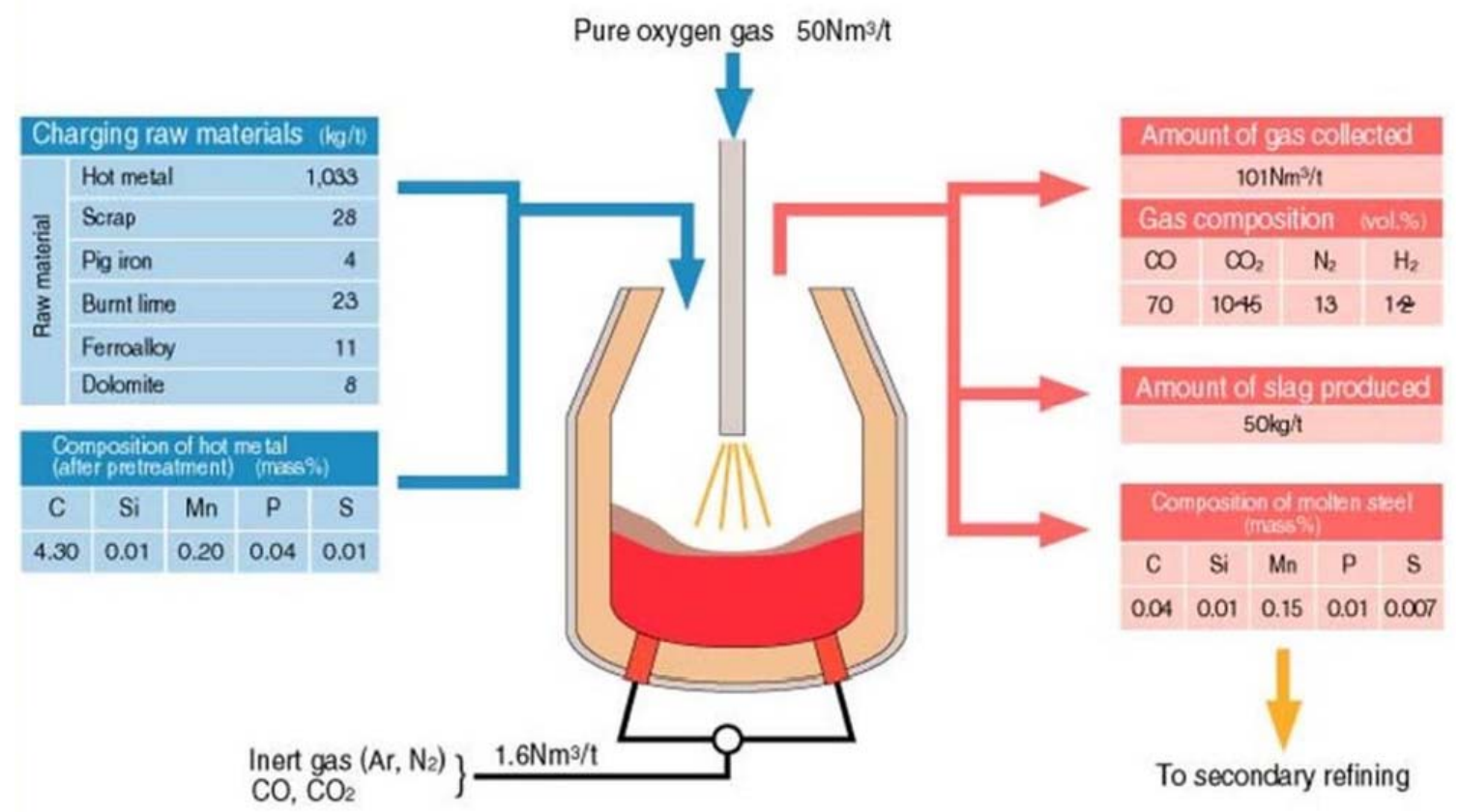

Figure 1. Schematic BOF process [1]

The metallurgy in the converter is the most widely used process for producing steel from liquid cast iron (hot metal). The process involves blowing oxygen through hot metal to reduce the carbon content by oxidizing metal.

The impingement of the oxygen jets at supersonic speed on the molten iron bath, results in metal droplets being ejected from the bath by impact, thereby increasing the metal surface area and the rate of oxidation of the impurities in molten iron.

Right at the beginning of each heat, scrap is charged into the converter along with hot metal to act as a coolant for the heat generated by the oxidation reactions. More often than not, iron ore is also added during the blow so that the oxidation of silicon, phosphorus, manganese and carbon, which are all exothermic reactions, do not result in inordinate increase in bath temperature.

\subsection{Use of Fluxes}

The oxidation reactions are exothermic and constitute the source of heat in BOF and BOS processes, leading to an increase in the bath temperature to $1.600-1.660^{\circ} \mathrm{C}$ at the end of refining, from an initial temperature of $1.250-1.300^{\circ} \mathrm{C}$.

Oxidation of $\mathrm{Si}, \mathrm{Fe}, \mathrm{Mn}, \mathrm{P}$ (and sometimes small amounts of $\mathrm{Ti}$ ) leads to the formation of $\mathrm{SiO}_{2}, \mathrm{FeO}, \mathrm{MnO}, \mathrm{P}_{2} \mathrm{O}_{5}$ (and $\mathrm{TiO}_{2}$ ). These oxide combine with lime, dunite and other 
slag forming agents which are added during the blow to form a slag capable of holding the impurities in the form of complex oxides.

Reduce the melting point of the slag, in order to form a basic slag and trap impurities, mainly sulphur and phosphorus:

- Simple behaviour: $\mathrm{CaO}$ and $\mathrm{MgO}$ react with $\mathrm{SiO}_{2}$ and $\mathrm{FeO}$ in the slag.

- If the pig iron has high quantities of $\mathrm{Si}$, will require a greater amount of fluxes. The quantity of $\mathrm{MgO}$ is designed in a way such as the final content in slag is between 8 and $10 \%$ to reduce erosion of the refractory linings.

\section{MATERIAL AND METHODS}

\subsection{PASEK Dunite}

PASEK Dunite is an ultramaphic rock exploited in the north of Spain with a basic chemical classification being olivine and serpentine its principal minerals. It is formed by orthopyroxene, clinopyroxene and olivine in variable proportion, with a previous amphibolitization of the rock and a paragenesis of hydrothermal alteration with serpentinization and talc conversion.

Exploited area corresponds with the less alteration zone (Figure 2). Rock has a grain size medium to high, equigranular, with frequent mesh textures in primary minerals developing secondary paragenesis. Through petrographic and geochemical study, following minerals and compositions are identified [2]:

- Orthopyroxene: Classified by composition as enstatite, (Mg1.7Fe0.2)(Si1.96Al0.04O6) with traces of $\mathrm{Ca}$, $\mathrm{Cr}$ y $\mathrm{Mn}$ (<0.1 a.p.f.u).

- Clinopyroxene: Classified by composition as diopside (Ca0.95Mg0.9)(Si1.94Al0.06O6), with traces of Ti, Fe y $\mathrm{Na}(<0.2$ a.p.f.u).

- Olivine: Classified as olivine with s.s. $\mathrm{Mg}^{2+}-\mathrm{Fe}^{2+}(\mathrm{Mg} 1.5 \mathrm{Fe} 0.5)\left(\mathrm{SiO}_{4}\right)$, with traces of $\mathrm{Al}$ (<0.01 a.p.f.u).

- Spinel: Classified as spinel showing solid solution between hercynite and magnesiochromite (Mg0.67Fe0.3)(Al1.55Cr0.32Fe0.1)O4.

- Opaque minerals: Generally magnetite and ilmenite with little size.

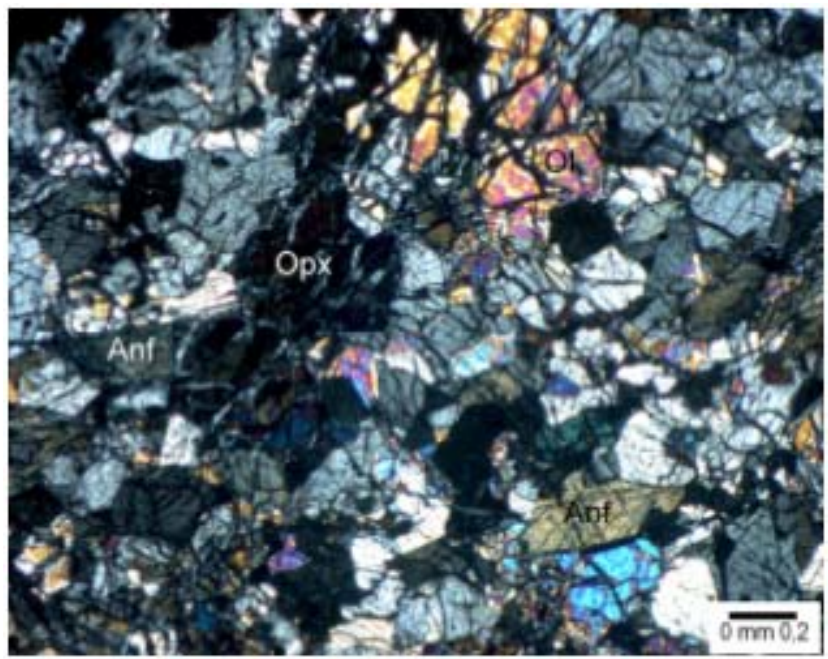

Figure 2. Micrograph with crossed nicols showing the texture of the rock [3]. 


\subsection{MgO Requirements}

Appropriated fluxes for the BOF could require low melting point to reduce the energy consumption, to reduce the energy to fluidity the slag at lower temperature and to melt at lower temperature than steel.

It is necessary a good result obtained in the Tumble test. It is required that the fluxes do not generate fines which could obstruct the blowing plugs, so we would have a homogeneous flux.

A homogeneous chemistry that allows to control the basicity ( $\mathrm{Si}$ and $\mathrm{MgO}$ levels) and a high absorption characteristics to combine the flux with $\mathrm{P}, \mathrm{S}, \mathrm{Si}$, etc. are necessary.

\section{RESULTS AND DISCUSSION}

\subsection{Why DUNITE is the Best Flux}

Dunite is a very homogeneous and hard stone. The main characteristics are:

- High hot and cold resistance to mechanical stress (shatter / crushing / abrasion).

- Softening and melting points of a flux, not a refractory material (Table 1).

- Large porosity which is increased more than $20 \%$ when dunite is heated at BOF process temperature, and high absorption level (Figure 3 ).

- Stable components with low melting points (Table 2).

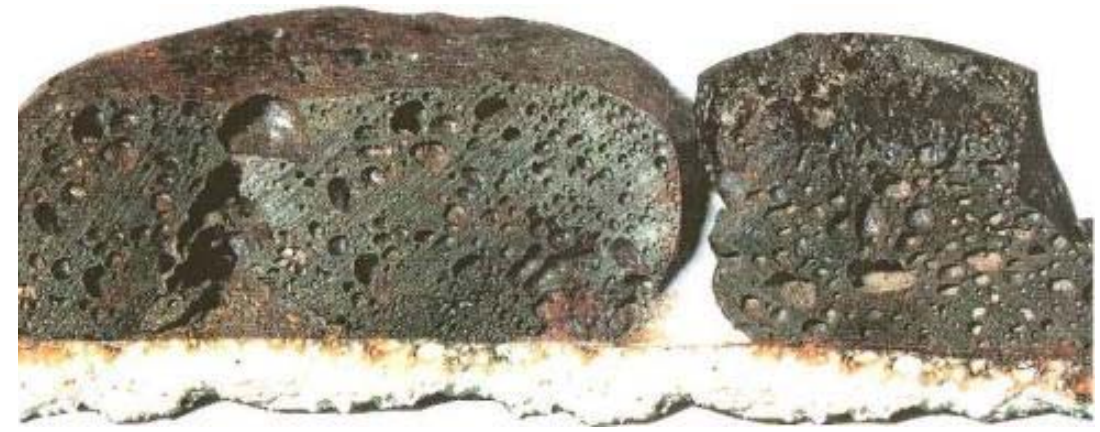

Figure 3. Aspect of a calcined dunite.

Table 1. Mechanical and thermic properties of dunite

\begin{tabular}{cccc}
\hline \multicolumn{2}{c}{ Mechanical properties } & \multicolumn{2}{c}{ Thermic properties } \\
\hline Property & Typical & Property & Typical \\
\hline Tumble test & 95 & Softening point & $1.200^{\circ} \mathrm{C}$ \\
\hline Hardness & $6.5 / 7$ Mohs scale & Melting point & $1.450^{\circ} \mathrm{C}$ \\
\hline
\end{tabular}

Table 2. Chemical analysis of PASEK Dunite

\begin{tabular}{lc}
\hline \multicolumn{2}{c}{ Chemical analysis } \\
\hline Component & Typical \\
\hline $\mathrm{MgO}$ & $37 \%$ \\
\hline $\mathrm{SiO}_{2}$ & $40.5 \%$ \\
\hline $\mathrm{Fe}_{2} \mathrm{O}_{3}$ & $8.3 \%$ \\
\hline $\mathrm{CaO}$ & $1.9 \%$ \\
\hline $\mathrm{Na}_{2} \mathrm{O}+\mathrm{K}_{2} \mathrm{O}$ & $<0.20 \%$ \\
\hline $\mathrm{L} . \mathrm{O} . \mathrm{I}$. & $8.5 \%$ \\
\hline
\end{tabular}




\subsection{Highest Value in Use of Lumps in BOF}

The dunite used as a flux in the blast furnace has no fines. It is very lumpy material. The $93 \%$ of the total material is between 15 to $40 \mathrm{~mm}$. There is only $2 \%$ of the total below $10 \mathrm{~mm}$. Dunite is strong and lumpy so no powder (Figure 4).

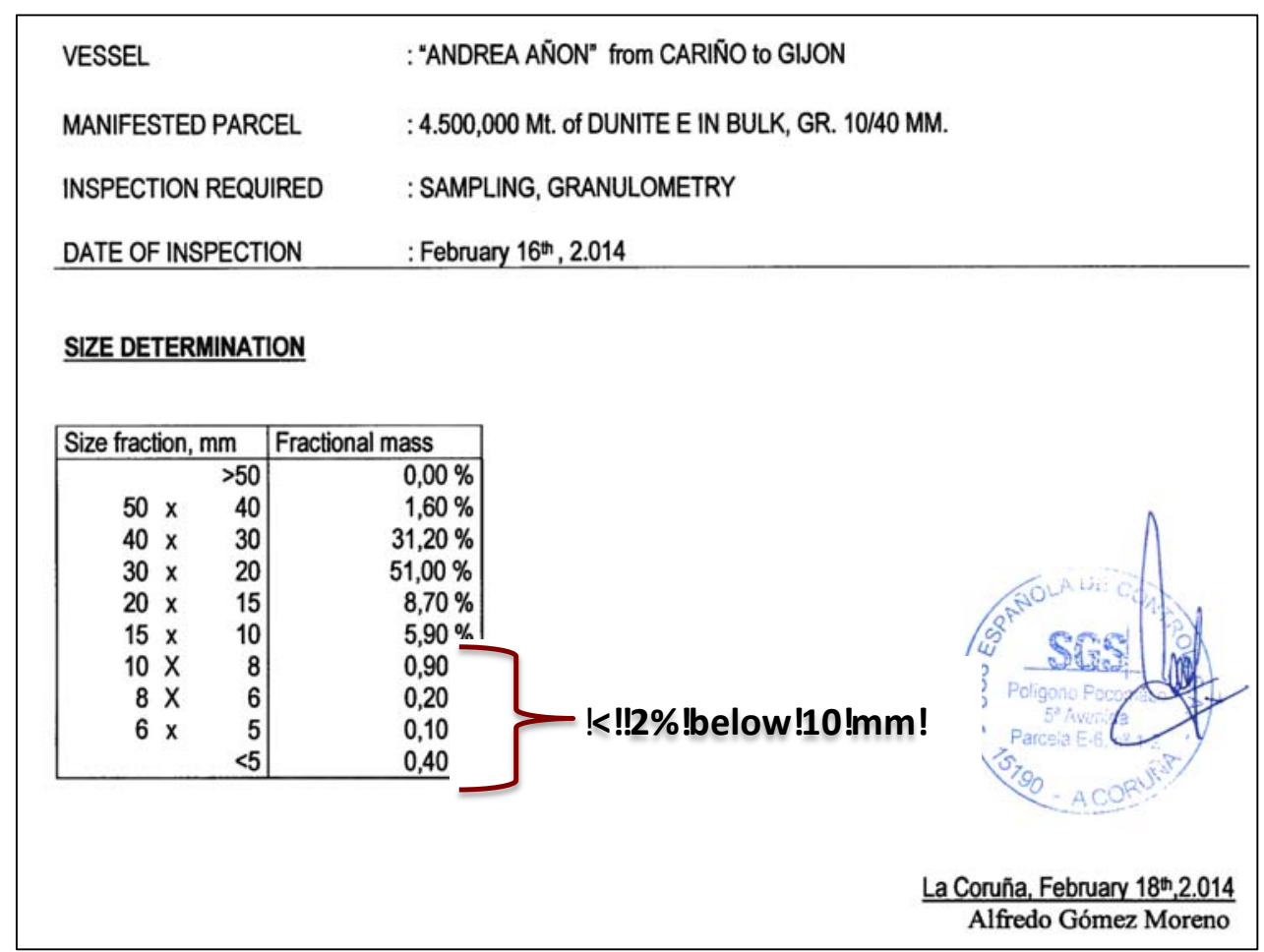

Figure 4. Sieve analysis of a typical PASEK Dunite used in BOF process.

Also, the use of dunite in this kind of process allows to save money due to less energy consumption. In the next figure, the energy consumption of different fluxes to heat them from 22 to $1.400^{\circ} \mathrm{C}$ is shown. The dolomite energy consumption is about $45 \%$ higher than dunite consumption so is possible to save money using dunite instead of dolomite as a flux in the BOF process (Figure 5).

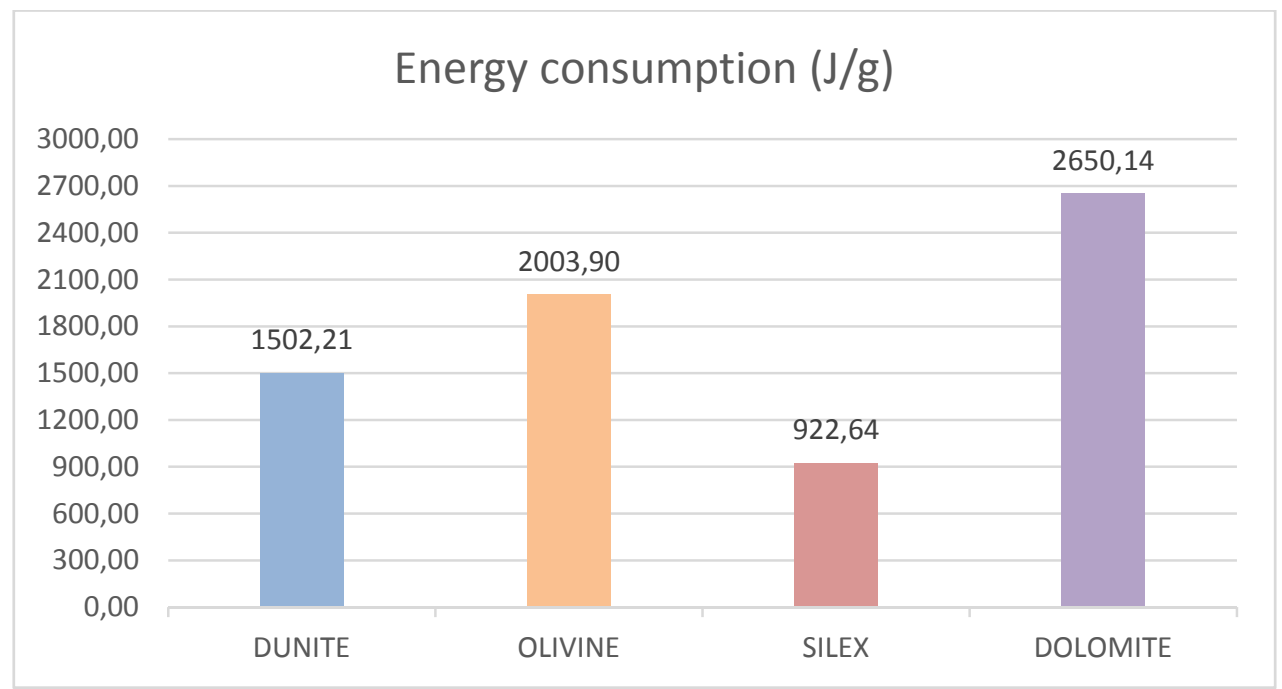

Figure 5. Results of the thermogravimetric analysis for different fluxes used in BOF process. 


\subsection{Magnesium Silicate Behaviour in the BOF Process}

Taking into account the working conditions in the BOF (reducing atmosphere), magnesium silicate that can be used as a flux will be subject to blast furnace similar conditions. In studies with experimental blast furnaces have seen that the magnesium silicates undergoes a series of reactions with the molten metal and its impurities, to form a siliceous melt to trap undesired elements.

In the early stages, magnesium silicate develops a border with magnetite and liquid phase that gradually develops phases as wustite, magnesiumferrite and sodium and potassium silicates passing to the slag (Figure 6). The cast with free silica also helps trapping impurities. In the final stages, the magnesium silicates is completely dissolved and its components become part of the slag and influence their behaviour.
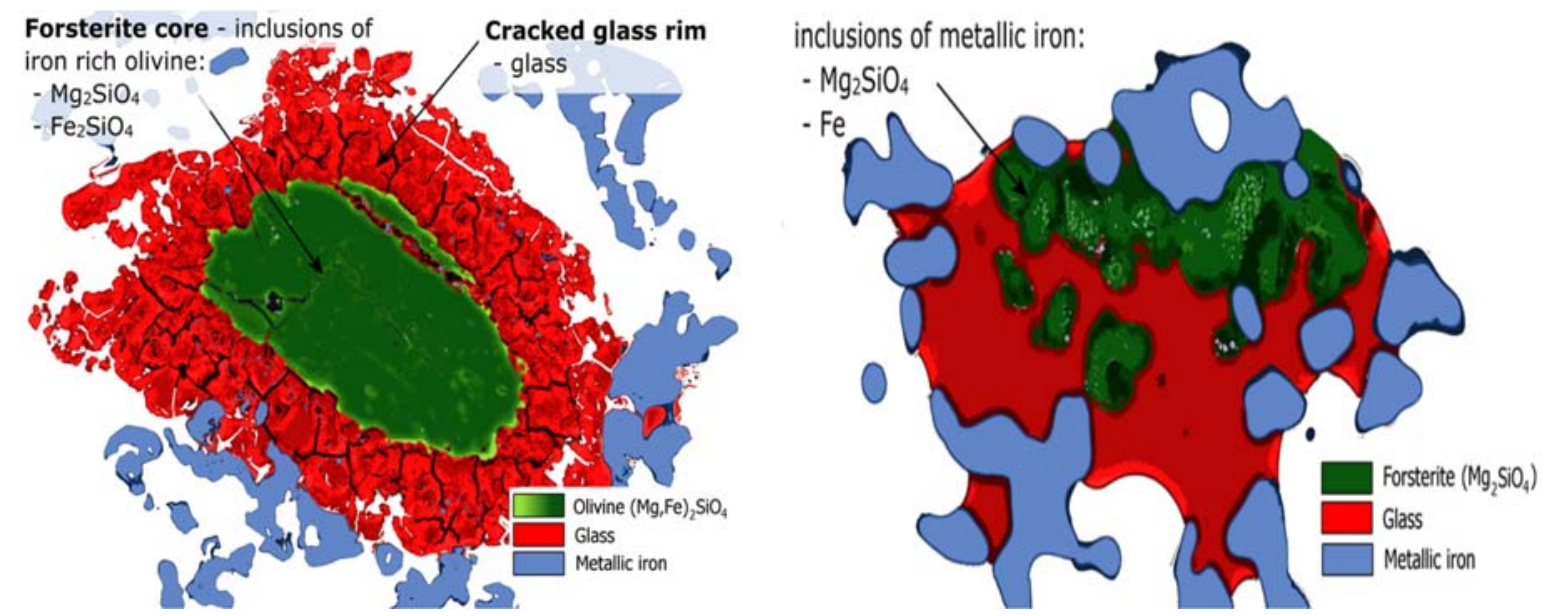

Figure 6. In the left picture, the silicate has not reacted completely and is surrounded by a rim of glass (melt) of siliceous composition, with some magnesium and iron oxides. In the right picture, magnesium silicate has almost completely consumed, giving place to a melt surrounded by droplets of metallic iron which can be in turn surrounded by a siliceous melt [4].

\subsection{Hot Metal Ratio}

An important parameter in this kind of process is the ratio pig iron/scrap (Hot Metal Ratio, HMR). This parameter shows the thermal balance of the process and measures the consumption of pig iron per tonne of liquid steel.

- Low HMR: lot of scrap and slightly pig iron. Could not be enough energy so it is necessary to add extra energy: anthracite stones, ferrosilicate, etc. It is interesting that the fluxes not consume energy as the calcined dolomite, to maximize the scrap consume.

- High HMR: There are enough energy. It is necessary to add other elements to control the temperature so material with some iron amount are introduced. It is important that this material is not scrap because the HMR could change and this parameter is fixed in each steel plant. Is possible to use green dolomite that is calcined due to the extra energy.

The slag basicity and the amount of slag produced have influence in the dephosphorization. Phosphorus is not really disappear but goes to slag. The greater amount of slag produced, the greater amount of phosphorus removed but the productivity of the process decreases. 
With high hot metal ratio, more phosphorus amount is necessary to remove in comparison with a low hot metal ratio because this phosphorus enters by the pig iron and not by the scrap, so is necessary high amount of slag.

It is necessary to increase the slag amount maintaining the basicity and the MgO level. In this case would be possible to use dunite: it could be possible to use dunite to dephosphorization process because is necessary high slag quantity.

For a constant HMR, if seeks to reduce the Si level, I have less Si in the converter so, maintaining a constant basicity the slag amount would be too low for dephosphorization. Is necessary to add any fluxes that allows carrying it out.

\section{CONCLUSION}

PASEK Dunite is a good flux in BOF process and its use is recommended if:

1. Pig iron with low Si content is produce.

2. It is possible to use dunite when high levels of slag, maintaining the basicity index and the $\mathrm{MgO}$ amount, are necessary. In this case, there are high amount of phosphorous to remove (High HMR) so the dunite is effective to make it.

3. It is necessary to increase slag production in the BOF process.

\section{Acknowledgments}

Geology Department. University of Oviedo.

\section{REFERENCES}

1 Industrial Efficiency Technology Database [website]. JFE 21 $1^{\text {st }}$ Century Foundation, 2003 [access: March,1st]. Available at http://ietd.iipnetwork.org/content/bof-bottom-stirring

2 Corretgé Castañon, L.G., Rubio Ordóñez, A. Transformación mineral en procesos de calentamiento. Estudio térmico difractográfico de una muestra de dunite. Oviedo: University of Oviedo; 2011.

3 Caballero, R., Rubio, A., García-Ariass, M., Corretgé, L.G. Utilización de la dunita a temperaturas elevadas. Comportamiento térmico de las fases hidratadas. University of Oviedo and Pasek Minerales; 2010.

4 Ryösä, E. Mineral reactions and slag formation during reduction of olivine Blast Furnace pellets. Dissertations from the Faculty of Science and Technology, 2008. Uppsala Universitet, 575 